\title{
Cancer stem cell subsets and their relationships
}

\author{
Hai-Guang Liu, Chong Chen, Han Yang, Yi-Fei Pan ${ }^{*}$ and Xiao-Hua Zhang ${ }^{*}$
}

\begin{abstract}
Emerging evidence suggests that cancer stem cells account for the initiation and progression of cancer. While many types of cancer stem cells with specific markers have been isolated and identified, a variety of differences among them began to be appreciated. Cancer stem cells are hierarchical populations that consist of precancerous stem cells, primary cancer stem cells, migrating cancer stem cells and chemoradioresistant cancer stem cells, playing different roles in cancer initiation and progression. Here we propose a new concept "horizontal hierarchy of cancer stem cells" to distinguish them from vertical hierarchy cancer stem cells, cancer transient-amplifying cells and cancer differentiated cells, and summarize our current understanding of these subsets of cancer stem cells with the aim to open up novel therapeutic strategies for cancer based on this understanding.
\end{abstract}

\section{Introduction}

Cancer is a kind of abnormal tissue that develops the ability of unlimited growth and the resistance to various survival stresses. Recently, accumulating experimental evidence supports that cancer stem cells account for the initiation and progression of cancer, which challenges the classical stochastic model of cancer development [1]. The cancer stem cell model or intrinsic model posits similar differentiation hierarchy such as hematopoietic system, cancer stem cells, cancer transient-amplifying (TA) cells and cancer differentiated cells, which is defined as vertical hierarchy here. Only cancer stem cells or cancer TA cells that reacquire self-renewal property can initiate cancer and progress into more malignant disease. However, in the stochastic model no hierarchy in cancer exists and every single cancer cell has the capacity of initiation and progression. Cancer stem cell hypothesis suggests that targeted therapy to cancer stem cells, not cancer TA cells and cancer differentiated cells, is the best measure to eradicate cancer, because traditional cancer therapies target the cancer TA cells and cancer differentiation cells, but omit cancer stem cells, thus leading to frequent cancer relapse [2].

The essential features of cancer stem cells are selfrenewal, multi-differentiation and tumorigenic capacity [3]. Cancer stem cells are also able to migrate and resist chemotherapy and radiotherapy. However, cancer stem cells are in constant evolution and these capacities are

\footnotetext{
* Correspondence: panyifwzmc@yahoo.com; zhangxhwzmc@yahoo.com
Department of Oncology, The First Affiliated Hospital of Wenzhou Medical

* Correspondence: panyifwzmc@yahoo.com; zhangxhwzmc@yahoo.com College, Wenzhou, 325000, China
}

(c) 2011 Liu et al; licensee BioMed Central Ltd. This is an Open Access article distributed under the terms of the Creative Commons Attribution License (http://creativecommons.org/licenses/by/2.0), which permits unrestricted use, distribution, and reproduction in any medium, provided the original work is properly cited. different among different populations of cancer stem cells. Thus we propose a horizontal hierarchy that comprises precancerous stem cells, primary cancer stem cells, migrating cancer stem cells and chemoradioresistant cancer stem cells (Figure 1). Below we will describe the horizontal hierarchy of cancer stem cells and discuss the relationship among these subsets of cancer stem cells.

\section{Primary cancer stem cells}

Cancer cells with features of stem cells were discovered by Rudolf Virchow in the mid-19th century, who found that some cancer cells had the histological characteristics, proliferation and differentiation capacity similar to embryonic cells [4]. In 1937, Jacob Furth and Morton Kahn transplanted human leukemia cells into mice and found that the tumorigenesis of leukemia cells was different from each other. In 1960s-1970s, based on spleen-colony forming tests numerous studies showed that the tumorigenesis of cancer cells was different not only in leukemia, but also in many types of solid tumors [5-8]. Thus it is speculated that cancer, a new type of stem cell disease, was initiated from transformed stem cells and developed as a heterogeneity tissue, containing cancer stem cell subpopulations and differentiated cancer cell subpopulations.

The invention of flow cytometry greatly helped the use of specific markers to isolate subsets of cells [9]. In 1997, Bonnet et al [10] isolated two groups of leukemia cells from leukemia patients with specific surface markers CD 34 and $\mathrm{CD} 38$, and found that $\mathrm{CD} 34^{+} \mathrm{CD} 38^{-}$ 


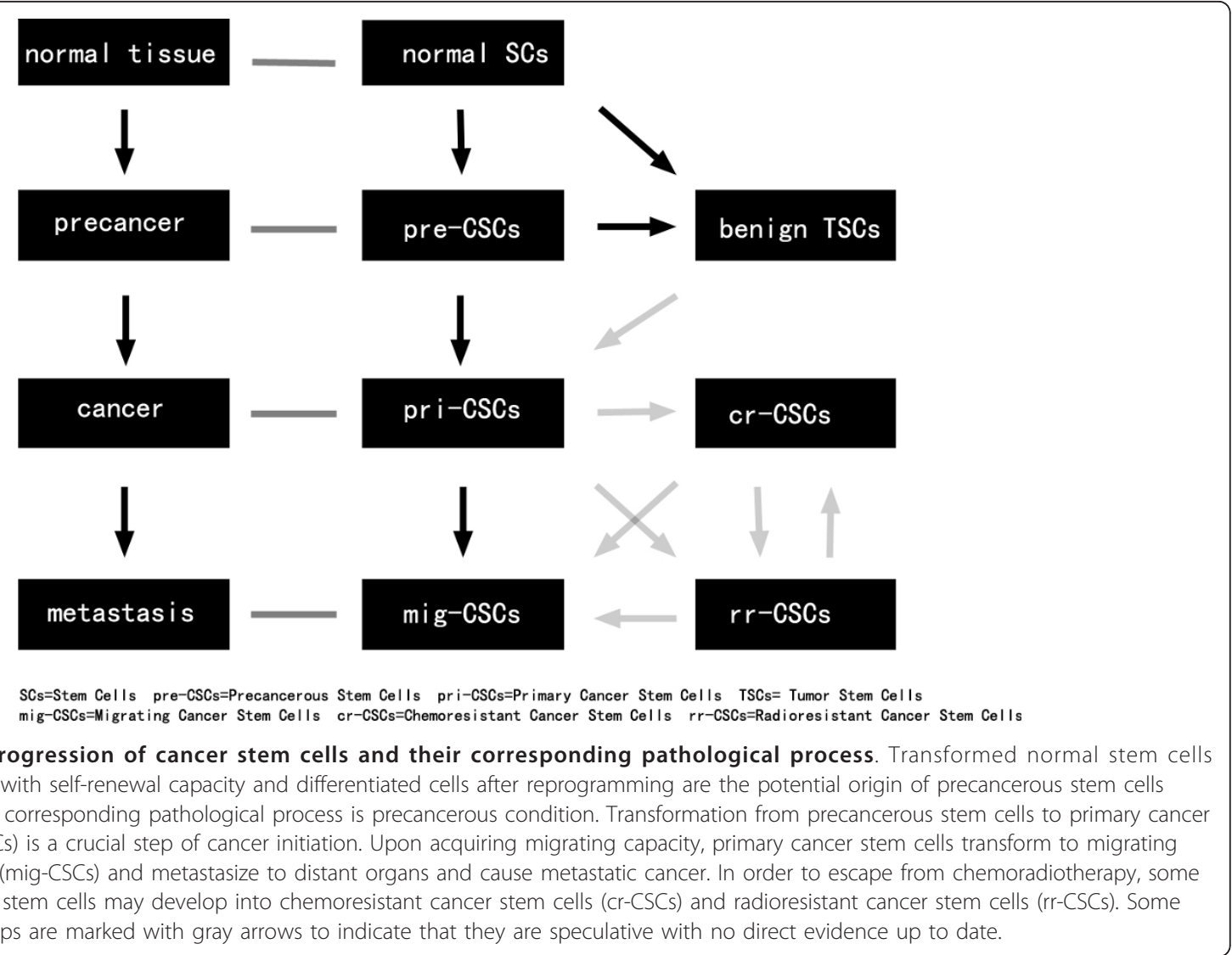

leukemia cells had the capacity of self-renewal and multi-differentiation similar to hematopoietic stem cells, and developed tumor more quickly than $\mathrm{CD} 34^{-} \mathrm{CD} 38^{+}$ leukemia cells. Thus they concluded that $\mathrm{CD} 34^{+} \mathrm{CD} 38^{-}$ subpopulations were the initiating cells of leukemia. This was the first experimental evidence of cancer stem cells. Later, Al-Hajj et al. [11] isolated $\mathrm{CD} 44^{+} \mathrm{CD} 24^{-}$ breast cancer stem cells from breast cancer patients in 2003, thus providing the first experimental evidence of solid tumor stem cells. After that, more types of solid tumor stem cells were isolated with specific surface markers (Table 1 [12-59]).

Interestingly, $\mathrm{Xu}$ et al [60] discovered a type of benign tumor stem cells by isolating a type of stem-like cells from pituitary adenoma with self-renewal, multi-lineage differentiation and neurospheres formation capacity. Compared with differentiated daughter cells, pituitary adenoma stem cells expressed high levels of stem cellrelated proteins, anti-apoptotic proteins and pituitary progenitor markers, and had a stronger resistance to chemotherapy. Differentiation of pituitary adenoma stem cells could respond to hypothalamic hormones and secret the corresponding pituitary hormones, which were phenotypes of primary pituitary adenoma. Besides these capacities, pituitary adenoma stem cells could form tumors in the continuous xenotransplanation assays. This was the first experimental evidence of the existence of benign tumor stem cells.

At present, many types of primary cancer stem cells with specific surface markers have been isolated and the cancer stem cell hypothesis is widely accepted. However, many questions remain in the field of cancer stem cells research. For example, where primary cancer stem cells initiate from; whether primary cancer stem cells are same in the same type of cancer among different patients; and how to distinguish cancer stem cells from normal stem cells. Below, we will focus on the origin and the fate of primary cancer stem cells.

\section{Precancerous stem cells}

Based on current literature, primary cancer stem cells may be derived from precancerous stem cells. Chen et al [61] reported the isolation of a type of precancerous stem cells from dendritic cell-like leukemic mice and the establishment of this precancerous stem cell line. The precancerous stem cells had stem cell-like phenotype, unlimited self-renewal, multi-differentiation and could reconstruct the hematopoietic system of mice after deadly radiation treatment. Transplantation of such precancerous stem cells could form tumor in immune-deficient but not in 
Table 1 Cancer stem cells with specific markers

\begin{tabular}{|c|c|c|}
\hline Type of cancer & Specific markers & References \\
\hline AML & $\mathrm{CD}^{2} 4^{+} \mathrm{CD}^{-1} \mathrm{Lin}^{-}$ & {$[10]$} \\
\hline AML & $\mathrm{CD}_{123^{+}}$ & {$[12,13]$} \\
\hline AML & $\mathrm{CD} 47^{+}$ & [14] \\
\hline Breast cancer & CD24-CD44 $4^{+}$Lin $^{-}$ & {$[11,15]$} \\
\hline Breast cancer & $\mathrm{ALDH}^{+}$ & {$[16,17]$} \\
\hline Brain tumors & $\mathrm{CD}_{133^{+}}$ & [18-20] \\
\hline Glioblastoma & SSEA- $1^{+}$ & [21] \\
\hline Glioblastoma & $\mathrm{A} 2 \mathrm{~B} 5^{+}$ & [22] \\
\hline Prostate cancer & $\mathrm{a} 2 \beta 1^{\mathrm{hi}} \mathrm{CD} 133^{+}$ & [23] \\
\hline Prostate cancer & Lin'Sca- $1^{+} \mathrm{CD}_{49} \mathrm{f}^{\text {high }}$ & [24] \\
\hline Bladder cancer & $\mathrm{ALDH}^{+}$ & {$[25]$} \\
\hline Lung cancer & $\mathrm{SP}_{-} \mathrm{C}^{+} \mathrm{CCA}^{+}$ & {$[26]$} \\
\hline Lung cancer & CD133+ & [27] \\
\hline Lung cancer & $\mathrm{ALDH}^{+}$ & {$[28]$} \\
\hline Melanoma & $\mathrm{CD}^{2} \mathrm{O}^{+} \mathrm{MCAM}^{+}$ & [29] \\
\hline Melanoma & $\mathrm{CD}_{133^{+}} \mathrm{ABCG}^{+}$ & [30] \\
\hline Melanoma & $\mathrm{MDR}^{+}$ & [31] \\
\hline Melanoma & $\mathrm{ABCG}^{+}$ & [32] \\
\hline Melanoma & $\mathrm{CD} 271^{+}$ & [33] \\
\hline Melanoma & $\mathrm{JARID1B}^{+}$ & [34] \\
\hline Colon cancer & CD133 ${ }^{+}$ & {$[35-38]$} \\
\hline Colon cancer & $\operatorname{Lgr}^{+}$ & [39] \\
\hline Colon cancer & $\mathrm{ALDH}^{+}$ & {$[40]$} \\
\hline Colorectal cancer & $\mathrm{CD} 44^{+} \mathrm{ESA}^{\mathrm{hi}} \mathrm{CD} 166^{+}$ & [41] \\
\hline Colorectal cancer & $\mathrm{CD}_{2} 6^{+}$ & {$[42]$} \\
\hline Intestinal cancer & $\operatorname{Lgr5}^{+}$ & [39] \\
\hline Intestinal cancer & $\mathrm{CD}_{133^{+}}$ & [43] \\
\hline Pancreatic cancer & $\mathrm{CD}_{4} 4^{+} \mathrm{CD} 24^{+} \mathrm{ESA}^{+}$ & [44] \\
\hline Pancreatic cancer & $\mathrm{CD}_{133^{+}}$ & [45] \\
\hline HNSCC & $\mathrm{CD}_{4} 4^{+}$ & [46] \\
\hline HNSCC & $\mathrm{ALDH}^{+}$ & [47] \\
\hline B-precursor ALL & $\begin{array}{c}\mathrm{CD} 34^{+} \mathrm{CD} 38^{+} \mathrm{CD}^{\mathrm{C}} 9^{+} ; \mathrm{CD} 4^{+} \mathrm{CD} 8^{-} \\
\mathrm{CD} 19^{+}\end{array}$ & [48] \\
\hline Ovarian cancer & $\mathrm{CD} 44^{+} \mathrm{CD} 117^{+}$ & [49] \\
\hline Ovarian cancer & $\mathrm{CD}_{133^{+}}$ & {$[50]$} \\
\hline $\begin{array}{l}\text { Endometrial } \\
\text { tumors }\end{array}$ & $\mathrm{CD}_{133^{+}}$ & [51] \\
\hline Liver cancer & $\mathrm{CD} 0^{+}$ & [52] \\
\hline Liver cancer & $\mathrm{CD}_{133^{+}}$ & [53] \\
\hline Liver cancer & $\mathrm{EpCAM}^{+}$ & [54] \\
\hline Renal carcinomas & $\mathrm{CD} 105^{+}$ & {$[55]$} \\
\hline Medulloblastoma & $\mathrm{CD} 15^{+}$ & {$[56,57]$} \\
\hline Gastric cancer & $\mathrm{CD}_{4} 4^{+}$ & [58] \\
\hline Osteosarcoma & Oct- $4^{+}$ & {$[59]$} \\
\hline
\end{tabular}

AML: acute myeloid leukaemia; ALDH: aldehyde dehydrogenase; SP-C: surfactant protein C; CCA: also known as CC10 or CCSP; MCAM: melanoma cell adhesion molecule; ABCG: ATP-binding cassette superfamily G member; MDR: multi-drug resistance protein; ESA: epithelial specific antigen; HNSCC: head and neck squamous cell carcinoma; ALL: acute lymphocytic leukaemia. immune-competent mice. In the evolution of the tumor, the phenotype and genotype of precancerous stem cells had developed towards primary cancer stem cells.

Interestingly, Shen et al [62] discovered that the precancerous stem cells could differentiate into tumor vasculogenic progenitors and generate most of the blood vessels. Precancerous stem cells sustained the expression of vascular growth factor receptor VEGRF-2, which was under the regulation of hypoxia and various vascular growth factors such as GM-CSF, Flt3L, and IL-13, to promote vasculogenesis. In contrast, the expression of VEGRF-2 was much lower in differentiated tumor cells, indicating that vasculogenesis in precancerous stem cells is related to their inherent stem-cell characteristics.

In our opinion, precancerous stem cells have the following characteristics. First, they hide themselves in precancerous lesions. It is well known that carcinogenesis is a multi-step process. For instance, colon cancer goes through mild, moderate and severe dysplasia, adenoma, carcinoma in situ, to invasive cancer and metastasis [63]. During this long process of carcinogenesis, precancerous stem cells undergo the transformation from normal stem cells to primary cancer stem cells. Precancerous lesions progress to cancer when precancerous stem cells transform into primary cancer stem cells [64]. Second, precancerous stem cell is a mutated stem cell that highly express stemness factors such as OCT3/4, SOX2, KLF4 and therefore develops the capacities of self-renewal, multi-differentiation and resistance to chemoradiotherapy [65]. Third, precancerous stem cells are subjected to modulation by micro-environment. They can transform into malignant tumors or benign disease, mainly depending on their communication with the micro-environment $[61,66]$.

Based on the three characteristics described above, we can distinguish precancerous stem cells from primary cancer stem cells. First is the location. Precancerous stem cells mainly exist in precancerous lesions, but primary cancer stem cells exist in primary cancer foci. For example, ductal carcinoma in situ (DCIS) is generally considered a type of precancerous lesion of breast invasive ductal carcinoma (IDC). The precancerous stem cells in DCIS stage are confined within the duct, but develop invasive capacity upon hypoxia or other stimuli, contributing to the progression of DCIS to IDC. Therefore, precancerous stem cells develop into primary cancer stem cells, and neoplastic ductal is not precanerous lesion but cancer foci [67]. Second is the genotype and phenotype. Primary cancer stem cells are derived from precancerous stem cells and exhibit some genotypes and 
phenotypes of precancerous stem cells, meanwhile they have their unique profiles. Castro and colleagues found that 126 genes were upregulated and 21 genes were downregulated in DCIS compared to IDC. Therefore, precancerous stem cells of DCIS exhibit different genotypes in contrast to primary cancer stem cells of IDC [68]. In addition, $\mathrm{Ma}$ et al. reported that the gene expression profiling of IDC was inherited from DCIS but developed distinct gene expression signatures [69]. With regard to epigenetic alternations, DNA methylation is notable. Adenomatous polyps (APs) is generally considered as precancerous lesion of adenomatous carcionoma (AdCa). The aberrant DNA methylation can be completely reversed in APs, but not in AdCa by a nonsteroidal anti-inflammatory drug celecoxib [70], suggesting the different epigenetic profilings between precancerous stem cells in APs and primary cancer stem cells in AdCa. Third is the bi-transformation. Under different micro-environment, precancerous stem cells can transform into malignant tumors or benign disease [61]. Bi-transformation is the most important characteristic to distinguish precancerous stem cells from primary cancer stem cells. Mammary intraepithelial neoplasia outgrowths (MINOs) is a mouse model of DCIS. The culture of single cells from MINOs expressed bipotential for myoepithelial and luminal differentiation and formed unique three-dimensional 'MINOspheres'. When transplanted in vivo, MINOspheres were able to form DCIS or IDC under different micro-environment [66].

The next question is the origin of precancerous stem cells. Several studies suggested that cancer initiating cells may be responsible for the development of precancerous stem cells. Wang et al [71] reported that a subpopulation of Nkx3-1 positive luminal epithelial cells was capable of self-renewal in vivo, and such a single cell was able to reconstitute prostate tissue in grafts. When the tumor suppressor gene Pten was deleted in Nkx3-1 positive luminal epithelial cells, the populations rapidly formed high-grade intraepithelial neoplasm and carcinoma after androgen mediated regeneration of the prostate. Therefore, Nkx3-1 positive luminal epithelial cells were a type of prostate stem cells and mutation of tumor suppressor genes would lead to prostate carcinogenesis.

Additionally, Barker et al [72] and Zhu et al [43] discovered crypt stem cells as the origin of intestinal cancer. They demonstrated that Lgr5 positive or prominin1 positive subpopulations were intestinal stem cells. Deletion of Apc or activation of endogenous Wnt signaling in such intestinal stem cells led to their transformation to abnormal stem cells, resulting in intestinal neoplasm. However, when the same mutations occurred in transitamplifying cells without unlimited self-renewal capacity, the induced adenomas grew slowly and disappeared after long observation.
The malignant transformation of normal stem cells was also discovered in mesenchymal stem cells. Røsland et al [73] showed that after long term culture for 5-106 weeks, $45.8 \%$ of bone marrow derived human mesenchymal stem cells underwent spontaneous transformation. They lost differentiation potential, had increased telomerase activity, escaped senescence, demonstrated anchorage-independent growth and were capable of tumorigenesis in vivo.

Moreover, human embryonic stem (hES) cells can transform into abnormal stem cells. Werbowetski-Ogilvie et al [74] identified two variant hES cell lines ( $\mathrm{v}$ hESC-1 and v-hESC-2) with different features from their parents. These variants expressed higher levels of pluripotency markers Oct4 and SSEA3, less depended on exogenous growth factors, had decreased differentiation capacity in either hematopoietic or neural conditions, and had increased frequency of teratoma initiating cells, however, their teratoma cells did not metastasize to other organs upon in vivo transplantation. Therefore, variant hES cells undergo neoplastic progression and may be the origin of malignant teratoma stem cells.

Progenitor cells may be another origin of cancer initiating cells. Jamieson et al. [75] reported that during blast-crisis of chronic myelogenous leukemia (CML), granulocyte-macrophage progenitors acquired much stronger self-renewal property due to the activation of Wnt/ $\beta$-catenin pathway, and expressed BCR-ABL protein and expanded imatinib-resistant CML. Later other groups confirmed these findings [76,77]. Guibal et al [78] showed that in a murine model of acute promyelocytic leukemia (APL), a population of committed myeloid cells $\left(\mathrm{CD} 34^{+}, \mathrm{c}-\mathrm{kit}^{+}, \mathrm{Fc} \gamma \mathrm{RIII} / \mathrm{II}^{+}, \mathrm{Gr} 1^{\text {int }}\right)$ demonstrated enhanced self-renewal capacity through the down-regulation of the transcription factor CCAAT/ enhancer binding protein- $\alpha(C / E B P-\alpha)$ and were capable of efficiently generating leukemia in recipient mice. Krivtsov et al [79] reported a more detailed overview of the transformation from committed progenitor to cancer stem cells.

Self-renewal is the most essential feature of normal stem cells and cancer stem cells [80]. Notably, some mature differentiated cells can re-acquire self-renewal capacity after reprogramming and thus may be additional origin of tumor initiating cells. Takahashi and Yamanaka [81] reported that they could reprogramme mouse fibroblasts into induced pluripotent stem (iPS) cells by introducing four factors Oct $3 / 4$, Sox 2 , c-Myc and Klf-4. In vivo transplantation assay demonstrated that the iPS cells were able to form teratomas and it was speculated that the two oncogenes c-Myc and Klf- 4 might endow iPS cells with the capacity of tumorigenesis. More recent studies demonstrated that iPS cells could be induced from differentiated cells by chemicals 
or proteins without the use of viral vectors [82-89]. These iPS cells with capacity of tumorigenesis might be another origin of malignant teratoma stem cells.

Taken together, adult stem cells, embryonic stem cells, progenitors with unlimited self-renewal capacity, and induced pluripotent stem cells are the potential origins of cancer initiating cells.

\section{Migrating cancer stem cells}

Metastasis is a very important feature of malignant tumors, accounting for $90 \%$ death of tumor patients [90]. Metastasis is a multi-step process that involves progressive growth, vascularization, invasion, detachment, embolization, survival in the circulation, arrest, extravasation, evasion of the host defense and progressive growth [91]. Given its complicated nature, metastasis is far from being understood completely and many hypotheses have been proposed to elucidate the underlying mechanisms. In seed and soil theory it is speculated that metastasis is closely related to the characteristics of tumor types and metastatic sites. Different tumor cells tend to move to their specific distant organs, and different distant organs tend to accept specific tumor cells [91]. In 1980, Hart and Fldier [92] transplanted lung, ovarian and kidney tissues into subcutaneous and muscle of C57BL/6 mice, and then transplanted B16 melanoma cells into these mice after these transplanted tissue survived. They found tumor formation in the transplanted lung and ovarian but not kidney tissues. Importantly, there was no significant difference in the number of melanoma cells throughout the lung, ovarian and kidney tissues. This ruled out the influence of tumor cell numbers and further confirmed that metastasis is related with special distant organs.

According to cancer stem cell hypotheses, cancer stem cells are ideal seeds of metastasis. Stem cells are indeed ideal carrier of gene mutations and their accumulation. First, the initiating cell must be a cell with extensive divisions and the mutations will be not lost after several divisions. Second, the initiating cell must have long life with strong resistance to different external stress. In contrast, a mature differentiated cell is subject to senescence and death and can not be the initiator of cancer.

But not all cancer stem cells have the characteristic of migration. Hermann et al [45] reported that CD133 ${ }^{+} \mathrm{CXCR} 4{ }^{+}$subsets determined the migrating phenotype of pancreatic cancer, although both $\mathrm{CD} 133^{+} \mathrm{CXCR} 4^{+}$and CD $133^{+}$CXCR4 pancreatic cancer stem cells could form pancreatic cancer when transplanted into athymic mice. An inhibitor of CXCR4 could significantly reduce the metastasis in group $\mathrm{CD} 133^{+} \mathrm{CXCR} 4^{+}$mice. Furthermore,

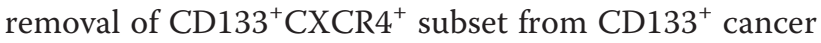
stem cells could disrupt the metastasis of pancreatic cancer, but did not affect tumorigenesis in primary organ.
Collectively, these data suggest that $\mathrm{CD} 133^{+} \mathrm{CXCR} 4^{+}$ cancer stem cells determine the metastasis and represent the migrating cancer stem cells of pancreatic cancer.

Furthermore, Yang et al [52] reported that $\mathrm{CD} 90^{+}$but not CD90- liver cancer cells were able to form tumor. Notably, $\mathrm{CD} 90^{+} \mathrm{CD} 44^{+}$subpopulations had stronger capacity of tumorigenesis and metastasis than $\mathrm{CD} 90^{+} \mathrm{CD} 44^{-}$ subpopulations, and the proportion of $\mathrm{CD} 90^{+} \mathrm{CD} 44^{+}$ subpopulations in metastasis increased compared to primary cancer. Therefore, $\mathrm{CD} 90^{+} \mathrm{CD} 44^{+}$subpopulations might be the migrating cancer stem cells of liver cancer.

However, current studies on migrating cancer stem cells are very limited, mainly due to the lack of specific migrating markers to isolate migrating cancer stem cells from primary cancer stem cells. It has been established that epithelial to mesenchymal transition (EMT) is involved in migration and metastasis, thus providing some clues on how to isolate migrating subpopulations from primary cancer stem cells. Mani et al [93] isolated $\mathrm{CD} 44^{\text {low }} \mathrm{CD} 24^{\text {high }}$ and $\mathrm{CD} 44^{\text {high }} \mathrm{CD} 24^{\text {low }}$ subpopulations from five breast cancer tissues and applied serial analysis of gene expression to reveal that $\mathrm{CD} 44^{\text {high }} \mathrm{CD} 24^{\text {low }}$ subpopulations expressed high level of mesenchymal markers N-cadherin, Vimentin, Fibronectin, Zeb2, Foxc2, Snail, Slug, Twist1 and Twist2, and low level of E-cadherin. They further transplanted human mammary epithelial cells constitutively expressing either Snail or Twist into immune-deficient mice and found that both of them had more efficiency of tumorigenesis, and the number of $\mathrm{CD} 44^{\text {high }} \mathrm{CD} 24^{\text {low }}$ subpopulations is elevated. Therefore, they concluded that EMT might be responsible for the generation of migrating cancer stem cells.

Zhang et al. [94] discovered that in three-dimensional culture, epithelial growth factor receptor tyrosine kinase inhibitor erlotinib inhibited the motility of inflammatory breast cancer (IBC) cell line SUM149 and its invasion in matrigel, accompanied with increased expression of E-cadherin and reduced expression of vimentin and $\beta$-catenin. Furthermore, they transplanted SUM149 cells into athymic nude mice and demonstrated that erlotinib inhibited the growth of tumor and lung metastasis by regulating the expression of E-cadherin and vimentin. This study suggests that erlotinib reversed EMT of IBC to inhibit metastasis. In this aspect, it is important to note a few of molecule implicated in both EMT and stemness such as Six1 [95,96] and p21CIP1 [97].

Based on these studies it is a potential approach to utilize mesenchymal markers to isolate migrating cancer stem cells from primary cancer stem cells.

\section{Other subsets of cancer stem cells}

One significant feature of cancer is its relapse after chemotherapy and radiation. This is because a few of cancer cells evolve with the capacity of resistance to 
chemotherapy and radiation. Whether primary cancer stem cells can evolve into chemoradioresistant cancer stem cells is not well known but recent studies provided indirect evidence for the existence of chemoradioresistant cancer stem cells.

\section{Chemoresistant cancer stem cells}

Todaro et al [98-100] reported a subpopulation of human colon cancer stem cells resistant to the most popular chemotherapeutic agent oxaliplatin or 5-fluorouracil (5-FU) at clinically relevant doses. Mechanistically, in this subpopulation interleukin-4 (IL-4) is produced in an autocrine manner to induce the expression of the antiapoptotic proteins cFLIP, Bcl-xL, and PED. The antagonist of IL-4 combined with oxaliplatin or 5-FU could effectively inhibit the growth of these cancer stem cells in vitro and in vivo, and decrease the size of spheroid and tumor.

ATP-binding cassette superfamily is one type of multi drug resistant proteins, which can pump chemotherapy drugs out of the cell and lead to chemoresistance $[101,102]$. ABCG2 is a member of this family and represents a purified marker of cancer stem cells [103]. However, targeted therapy with ABCG2 antagonist can only inhibit partially the growth of SP cells and cancer stem cells. This may be because cancer stem cells express other drug resistant proteins such as ABCB1 [104].

Despite these reports demonstrating the relationship between cancer stem cells and chemoresistance, further studies are crucial to provide direct evidence supporting the existence of chemoresistant cancer stem cells, which may help develop alternative strategy for chemotherapy and targeted therapy.

\section{Radioresistant cancer stem cells}

Diehn et al [105] reported that human and mouse breast cancer stem cells had lower levels of reactive oxygen species (ROS) than their non-tumorigenic progeny. Moreover, human cancer stem cells contained higher levels of antioxidant defense systems and developed less DNA damage after ionizing radiation, compared with non-tumor cells. Therefore, the heterogeneity of ROS levels in cancer stem cell subsets might contribute to their radioresistance. In addition, in CD133 positive glioma stem cells the expression of the autophagyrelated proteins LC3, ATG5 and ATG12 was increased as a response to $\gamma$-radiation [106]. Glioma stem cells and breast cancer stem cells could also escape from radiotherapy through preferential activation of the DNA damage response $[106,107]$. However, whether primary cancer stem cells contain a population of radioresistant subset remains unclear.

\section{Relationships among cancer stem cell subsets}

Up to now, precancerous stem cells, primary cancer stem cells and migrating cancer stem cells have been proven to exist in the progression of cancer $[45,52,61,62]$, while direct experimental evidence for the existence of chemoradioresistant cancer stem cells is still required. Based on current literature, precancerous stem cells may be originated from normal stem cells, progenitors which acquire unlimited self-renewal, or differentiated mature cells after reprogramming. They may exist in precancerous lesions and are able to transform into primary cancer stem cells or benign tumor stem cells depending on the microenvironment. While benign tumor stem cells may be originated from normal stem cells and become the driving force of growth and progression of benign tumor, it remains unknown whether benign tumor stem cells can be transformed into primary cancer stem cells (Figure 1).

Primary cancer stem cells may play the most important role in the progression of cancer and recurrence. Thus the transformation from precancerous stem cells to primary cancer stem cells is a crucial step in tumorigenesis. When primary cancer stem cells acquire migrating capacity through different mechanisms such as EMT, they metastasize to distant organs and cause metastatic cancer. Therefore, migrating cancer stem cells may be originated from primary cancer stem cells and this transition may be a key step of metastasis. In order to escape from chemoradiotherapy, primary cancer stem cells may develop into chemoradioresistant subsets, which is an important reason of chemoradioresistance and cancer recurrence after traditional chemotherapy and radiation therapy. Whether chemoradioresistant cancer stem cells can transform into migrating cancer stem cells is still not known.

\section{Conclusion}

In summary, based on the above discussion we propose the model shown in Figure 1 to demonstrate the relationship among the different subsets of cancer stem cells and their relevance to the pathological process of tumorigenesis. Undoubtedly, our deeper understanding of cancer stem cells subsets may help validate this model and open up novel therapeutic strategies for cancer. For example, we may attack migrating cancer stem cells to eliminate cancer metastasis, or eradicate chemoradioresistant cancer stem cells to overcome the resistance to chemotherapy and radiation therapy.

\section{Acknowledgements}

This work was supported by Social Development Research Project in Wenzhou (No. Y20090008) and Lucheng (No. S10107) 


\section{Authors' contributions}

LHG, CC, YH, PYF, ZXH all contributed to the development of the concept, literature review, discussions, and writing of the manuscript. All authors have read the manuscript and agree to its submission.

\section{Conflicts of interests}

The authors declare that they have no competing interests.

Received: 13 December 2010 Accepted: 4 May 2011 Published: 4 May 2011

\section{References}

1. La Porta C: Cancer stem cells: lessons from melanoma. Stem Cell Rev 2009, 5(1):61-5.

2. Rajan $P$, Srinivasan R: Targeting cancer stem cells in cancer prevention and therapy. Stem Cell Rev 2008, 4(3):211-6.

3. Sales K, Winslet M, Seifalian A: Stem cells and cancer: an overview. Stem Cell Rev 2007, 3(4):249-55.

4. Huntly B, Gilliland D: Leukaemia stem cells and the evolution of cancerstem-cell research. Nat Rev Cancer 2005, 5(4):311-21.

5. Bruce W, Van der Gaag H: A QUANTITATIVE ASSAY FOR THE NUMBER OF MURINE LYMPHOMA CELLS CAPABLE OF PROLIFERATION IN VIVO. NatUre 1963, 199:79-80.

6. Becker A, McCulloch E, Till J: Cytological demonstration of the clonal nature of spleen colonies derived from transplanted mouse marrow cells. Nature 1963, 197:452-4.

7. Park C, Bergsagel D, McCulloch E: Mouse myeloma tumor stem cells: a primary cell culture assay. J Natl Cancer Inst 1971, 46(2):411-22.

8. Hamburger A, Salmon S: Primary bioassay of human tumor stem cells. Science 1977, 197(4302):461-3.

9. Bonner $W$, Hulett $H$, Sweet $R$, et al: Fluorescence activated cell sorting. Rev Sci Instrum 1972, 43(3):404-9.

10. Bonnet $\mathrm{D}$, Dick J: Human acute myeloid leukemia is organized as a hierarchy that originates from a primitive hematopoietic cell. Nat Med 1997, 3(7):730-7.

11. Al-Hajj M, Wicha M, Benito-Hernandez A, et al: Prospective identification of tumorigenic breast cancer cells. Proc Natl Acad Sci USA 2003, 100(7):3983-8.

12. Jordan C: Unique molecular and cellular features of acute myelogenous leukemia stem cells. Leukemia 2002, 16(4):559-62.

13. Jin L, Lee EM, Ramshaw HS, et al: Monoclonal antibody-mediated targeting of CD123, IL-3 receptor alpha chain, eliminates human acute myeloid leukemic stem cells. Cell Stem Cell 2009, 5(1):31-42.

14. Majeti R, Chao MP, Alizadeh AA, et al: CD47 is an adverse prognostic factor and therapeutic antibody target on human acute myeloid leukemia stem cells. Cell 2009, 138(2):286-99.

15. Bauerschmitz G, Ranki T, Kangasniemi L, et al: Tissue-specific promoters active in CD44+CD24-/low breast cancer cells. Cancer Res 2008, 68(14):5533-9

16. Ginestier C, Hur M, Charafe-Jauffret $\mathrm{E}$, et al: ALDH1 is a marker of normal and malignant human mammary stem cells and a predictor of poor clinical outcome. Cell Stem Cell 2007, 1(5):555-67.

17. Charafe-Jauffret $E$, Ginestier C, lovino F, et al: Aldehyde dehydrogenase 1positive cancer stem cells mediate metastasis and poor clinical outcome in inflammatory breast cancer. Clin Cancer Res 2010, 16(1):45-55.

18. Singh $S$, Clarke I, Terasaki $M$, et al: Identification of a cancer stem cell in human brain tumors. Cancer Res 2003, 63(18):5821-8.

19. Singh S, Hawkins C, Clarke I, et al: Identification of human brain tumour initiating cells. Nature 2004, 432(7015):396-401.

20. Galli R, Binda E, Orfanelli U, et al: Isolation and characterization of tumorigenic, stem-like neural precursors from human glioblastoma. Cancer Res 2004, 64(19):7011-21.

21. Son M, Woolard K, Nam D, et al: SSEA-1 is an enrichment marker for tumor-initiating cells in human glioblastoma. Cell Stem Cell 2009, 4(5):440-52.

22. Tchoghandjian A, Baeza N, Colin C, et al: A2B5 cells from human glioblastoma have cancer stem cell properties. Brain Pathol 2010, 20(1):211-21.

23. Collins A, Berry P, Hyde C, et al: Prospective identification of tumorigenic prostate cancer stem cells. Cancer Res 2005, 65(23):10946-51.
24. Mulholland D, Xin L, Morim A, et al: Lin-Sca-1+CD49fhigh stem/ progenitors are tumor-initiating cells in the Pten-null prostate cancer model. Cancer Res 2009, 69(22):8555-62.

25. Su Y, Qiu Q, Zhang X, et al: Aldehyde dehydrogenase 1 A1-positive cell population is enriched in tumor-initiating cells and associated with progression of bladder cancer. Cancer Epidemiol Biomarkers Prev 2010, 19(2):327-37.

26. Kim C, Jackson E, Woolfenden A, et al: Identification of bronchioalveolar stem cells in normal lung and lung cancer. Cell 2005, 121(6):823-35.

27. Eramo A, Lotti F, Sette G, et al: Identification and expansion of the tumorigenic lung cancer stem cell population. Cell Death Differ 2008, 15(3):504-14.

28. Jiang F, Qiu Q, Khanna A, et al: Aldehyde dehydrogenase 1 is a tumor stem cell-associated marker in lung cancer. Mol Cancer Res 2009, 7(3):330-8.

29. Fang D, Nguyen $T$, Leishear $K$, et al: A tumorigenic subpopulation with stem cell properties in melanomas. Cancer Res 2005, 65(20):9328-37.

30. Monzani E, Facchetti F, Galmozzi E, et al: Melanoma contains CD133 and ABCG2 positive cells with enhanced tumourigenic potential. Eur J Cancer 2007, 43(5):935-46.

31. Keshet G, Goldstein I, Itzhaki O, et al: MDR1 expression identifies human melanoma stem cells. Biochem Biophys Res Commun 2008, 368(4):930-6.

32. Schatton $T$, Murphy $G$, Frank $N$, et al: Identification of cells initiating human melanomas. Nature 2008, 451(7176):345-9.

33. Boiko AD, Razorenova OV, van de Rijn $M$, et al: Human melanomainitiating cells express neural crest nerve growth factor receptor CD271. Nature 2010, 466(7302):133-7.

34. Roesch A, Fukunaga-Kalabis M, Schmidt EC, et al: A temporarily distinct subpopulation of slow-cycling melanoma cells is required for continuous tumor growth. Cell 2010, 141(4):583-94.

35. O'Brien C, Pollett A, Gallinger S, et al: A human colon cancer cell capable of initiating tumour growth in immunodeficient mice. Nature 2007, 445(7123):106-10.

36. Ricci-Vitiani L, Lombardi D, Pilozzi E, et al: Identification and expansion of human colon-cancer-initiating cells. Nature 2007, 445(7123):111-5.

37. Shmelkov S, Butler J, Hooper A, et al: CD133 expression is not restricted to stem cells, and both CD133+ and CD133- metastatic colon cancer cells initiate tumors. J Clin Invest 2008, 118(6):2111-20.

38. LaBarge M, Bissell M: Is CD133 a marker of metastatic colon cancer stem cells? J Clin Invest 2008, 118(6):2021-4.

39. Barker N, van Es J, Kuipers J, et al: Identification of stem cells in small intestine and colon by marker gene Lgr5. Nature 2007, 449(7165):1003-7.

40. Huang $E$, Hynes $M$, Zhang $T$, et al: Aldehyde dehydrogenase 1 is a marker for normal and malignant human colonic stem cells (SC) and tracks SC overpopulation during colon tumorigenesis. Cancer Res 2009, 69(8):3382-9.

41. Dalerba P, Dylla S, Park I, et al: Phenotypic characterization of human colorectal cancer stem cells. Proc Natl Acad Sci USA 2007, 104(24):10158-63.

42. Pang R, Law W, Chu A, et al: A subpopulation of CD26+ cancer stem cells with metastatic capacity in human colorectal cancer. Cell Stem Cell 2010, 6(6):603-15.

43. Zhu L, Gibson P, Currle D, et al: Prominin 1 marks intestinal stem cells that are susceptible to neoplastic transformation. Nature 2009, 457(7229):603-7.

44. Li C, Heidt DG, Dalerba P, et al: Identification of pancreatic cancer stem cells. Cancer Res 2007, 67(3):1030-7.

45. Hermann P, Huber S, Herrler T, et al: Distinct populations of cancer stem cells determine tumor growth and metastatic activity in human pancreatic cancer. Cell Stem Cell 2007, 1(3):313-23.

46. Prince M, Sivanandan R, Kaczorowski A, et al: Identification of a subpopulation of cells with cancer stem cell properties in head and neck squamous cell carcinoma. Proc Natl Acad Sci USA 2007, 104(3):973-8.

47. Chen $Y$, Chen $Y$, Hsu H, et al: Aldehyde dehydrogenase 1 is a putative marker for cancer stem cells in head and neck squamous cancer. Biochem Biophys Res Commun 2009, 385(3):307-13.

48. Kong Y, Yoshida S, Saito Y, et al: CD34+CD38+CD19+ as well as CD34 + CD38-CD19+ cells are leukemia-initiating cells with self-renewal capacity in human B-precursor ALL. Leukemia 2008, 22(6):1207-13. 
49. Zhang S, Balch C, Chan M, et al: Identification and characterization of ovarian cancer-initiating cells from primary human tumors. Cancer Res 2008, 68(11):4311-20.

50. Baba T, Convery P, Matsumura N, et al: Epigenetic regulation of CD133 and tumorigenicity of CD133+ ovarian cancer cells. Oncogene 2009, 28(2):209-18.

51. Rutella S, Bonanno G, Procoli A, et al: Cells with characteristics of cancer stem/progenitor cells express the CD133 antigen in human endometrial tumors. Clin Cancer Res 2009, 15(13):4299-311.

52. Yang Z, Ho D, Ng M, et al: Significance of CD90+ cancer stem cells in human liver cancer. Cancer Cell 2008, 13(2):153-66.

53. Suetsugu A, Nagaki M, Aoki $H$, et al: Characterization of CD133+ hepatocellular carcinoma cells as cancer stem/progenitor cells. Biochem Biophys Res Commun 2006, 351(4):820-4.

54. Terris B, Cavard C, Perret C: EpCAM, a new marker for cancer stem cells in hepatocellular carcinoma. J Hepatol 2010, 52(2):280-1.

55. Bussolati B, Bruno S, Grange C, et al: Identification of a tumor-initiating stem cell population in human renal carcinomas. FASEB J 2008, 22(10):3696-705

56. Read T, Fogarty M, Markant S, et al: Identification of CD15 as a marker for tumor-propagating cells in a mouse model of medulloblastoma. Cancer Cell 2009, 15(2):135-47.

57. Ward R, Lee L, Graham K, et al: Multipotent CD15+ cancer stem cells in patched-1-deficient mouse medulloblastoma. Cancer Res 2009, 69(11):4682-90.

58. Takaishi S, Okumura T, Tu S, et al: Identification of Gastric Cancer Stem Cells Using the Cell Surface Marker CD44. Stem Cells 2009, 27(5):1006-1020.

59. Levings $P, M c G a r r y ~ S$, Currie $T$, et al: Expression of an exogenous human Oct-4 promoter identifies tumor-initiating cells in osteosarcoma. Cancer Res 2009, 69(14):5648-55.

60. Xu Q, Yuan X, Tunici $P$, et al: Isolation of tumour stem-like cells from benign tumours. Br J Cancer 2009, 101(2):303-11.

61. Chen L, Shen R, Ye Y, et al: Precancerous stem cells have the potential for both benign and malignant differentiation. PLOS ONE 2007, 2(3): e293.

62. Shen $R, Y e Y, C$ hen $L$, et al: Precancerous stem cells can serve as tumor vasculogenic progenitors. PLOS ONE 2008, 3(2):e1652.

63. Fearon ER, Vogelstein B: A genetic model for colorectal tumorigenesis. Cell 1990, 61(5):759-67.

64. Grady WM, Carethers JM: Genomic and epigenetic instability in colorectal cancer pathogenesis. Gastroenterology 2008, 135(4):1079-99.

65. Bae KM, Su Z, Frye C, et al: Expression of pluripotent stem cell reprogramming factors by prostate tumor initiating cells. J Urol 2010, 183(5):2045-53.

66. Damonte $\mathrm{P}$, Hodgson J, Chen J, et al: Mammary carcinoma behavior is programmed in the precancer stem cell. Breast Cancer Res 2008, 10(3): R50.

67. Espina $V$, Liotta LA: What is the malignant nature of human ductal carcinoma in situ?". Nat Rev Cancer 2011, 11(1):68-75.

68. Castro NP, Osório CA, Torres $C$, et al: Evidence that molecular changes in cells occur before morphological alterations during the progression of breast ductal carcinoma. Breast Cancer Res 2008, 10(5):R87.

69. Ma XJ, Dahiya S, Richardson E, et al: Gene expression profiling of the tumor microenvironment during breast cancer progression. Breast Cancer Res 2009, 11(1):R7.

70. Shen $R$, Tao $L, X u Y$, et al: Reversibility of aberrant global DNA and estrogen receptor-alpha gene methylation distinguishes colorectal precancer from cancer. Int J Clin Exp Pathol 2009, 2(1):21-33.

71. Wang $X$, Kruithof-de Julio M, Economides $K$, et al: A luminal epithelial stem cell that is a cell of origin for prostate cancer. Nature 2009, 461(7263):495-500.

72. Barker N, Ridgway R, van Es J, et al: Crypt stem cells as the cells-of-origin of intestinal cancer. Nature 2009, 457(7229):608-11.

73. Røsland G, Svendsen A, Torsvik A, et al: Long-term cultures of bone marrow-derived human mesenchymal stem cells frequently undergo spontaneous malignant transformation. Cancer Res 2009, 69(13):5331-9.

74. Werbowetski-Ogilvie T, Bossé M, Stewart M, et al: Characterization of human embryonic stem cells with features of neoplastic progression. Nat Biotechnol 2009, 27(1):91-7.
75. Jamieson C, Ailles L, Dylla S, et al: Granulocyte-macrophage progenitors as candidate leukemic stem cells in blast-crisis CML. N Engl J Med 2004, 351(7):657-67

76. Minami $Y$, Stuart $S$, Ikawa T, et al: BCR-ABL-transformed GMP as myeloid leukemic stem cells. Proc Natl Acad Sci USA 2008, 105(46):17967-72

77. Stuart S, Minami Y, Wang J: The CML stem cell: evolution of the progenitor. Cell Cycle 2009, 8(9):1338-43.

78. Guibal F, Alberich-Jorda M, Hirai H, et al: Identification of a myeloid committed progenitor as the cancer-initiating cell in acute promyelocytic leukemia. Blood 2009, 114(27):5415-25.

79. Krivtsov A, Feng Z, Armstrong S: Transformation from committed progenitor to leukemia stem cells. Ann N Y Acad Sci 2009, 1176:144-9.

80. Dick J: Looking ahead in cancer stem cell research. Nat Biotechnol 2009, 27(1):44-6.

81. Takahashi K, Yamanaka S: Induction of pluripotent stem cells from mouse embryonic and adult fibroblast cultures by defined factors. Cell 2006, 126(4):663-76

82. Okita $\mathrm{K}$, Nakagawa $\mathrm{M}$, Hyenjong $\mathrm{H}$, et al: Generation of mouse induced pluripotent stem cells without viral vectors. Science 2008, 322(5903):949-53.

83. Stadtfeld M, Nagaya M, Utikal J, et al: Induced pluripotent stem cells generated without viral integration. Science 2008, 322(5903):945-9.

84. Yu JY, Hu KJ, Smuga-Otto K, et al: Human Induced Pluripotent Stem Cells Free of Vector and Transgene Sequences. Science 2009, 324(5928):797-801.

85. Kaji K, Norrby K, Paca A, et al: Virus-free induction of pluripotency and subsequent excision of reprogramming factors. Nature 2009, 458(7239):771-5.

86. Lyssiotis C, Foreman R, Staerk J, et al: Reprogramming of murine fibroblasts to induced pluripotent stem cells with chemical complementation of Klf4. Proc Natl Acad Sci USA 2009, 106(22):8912-7.

87. Zhou H, Wu S, Joo J, et al: Generation of induced pluripotent stem cells using recombinant proteins. Cell Stem Cell 2009, 4(5):381-4.

88. Kim D, Kim C, Moon J, et al: Generation of human induced pluripotent stem cells by direct delivery of reprogramming proteins. Cell Stem Cell 2009, 4(6):472-6.

89. Li W, Wei W, Zhu S, et al: Generation of rat and human induced pluripotent stem cells by combining genetic reprogramming and chemical inhibitors. Cell Stem Cell 2009, 4(1):16-9.

90. Weigelt B, Peterse J, van't Veer L: Breast cancer metastasis: markers and models. Nat Rev Cancer 2005, 5(8):591-602.

91. Fidler I: The pathogenesis of cancer metastasis: the 'seed and soil' hypothesis revisited. Nat Rev Cancer 2003, 3(6):453-8.

92. Hart I, Fidler I: Role of organ selectivity in the determination of metastatic patterns of B16 melanoma. Cancer Res 1980, 40(7):2281-7.

93. Mani S, Guo W, Liao M, et al: The epithelial-mesenchymal transition generates cells with properties of stem cells. Cell 2008, 133(4):704-15.

94. Zhang D, LaFortune T, Krishnamurthy S, et al: Epidermal growth factor receptor tyrosine kinase inhibitor reverses mesenchymal to epithelial phenotype and inhibits metastasis in inflammatory breast cancer. Clin Cancer Res 2009, 15(21):6639-48.

95. McCoy $E$, Iwanaga $R$, Jedlicka $P$, et al: Six 1 expands the mouse mammary epithelial stem/progenitor cell pool and induces mammary tumors that undergo epithelial-mesenchymal transition. J Clin Invest 2009, 119(9):2663-77.

96. Radisky D: Defining a role for the homeoprotein Six 1 in EMT and mammary tumorigenesis. J Clin Invest 2009, 119(9):2528-31.

97. Liu M, Casimiro M, Wang C, et al: p21CIP1 attenuates Ras- and c-Mycdependent breast tumor epithelial mesenchymal transition and cancer stem cell-like gene expression in vivo. Proc Natl Acad Sci USA 2009, 106(45):19035-9.

98. Todaro M, Alea M, Di Stefano A, et al: Colon cancer stem cells dictate tumor growth and resist cell death by production of interleukin-4. Cell Stem Cell 2007, 1(4):389-402.

99. Todaro M, Perez Alea M, Scopelliti A, et al: IL-4-mediated drug resistance in colon cancer stem cells. Cell Cycle 2008, 7(3):309-13.

100. Francipane $M$, Alea $M$, Lombardo $Y$, et al: Crucial role of interleukin-4 in the survival of colon cancer stem cells. Cancer Res 2008, 68(11):4022-5.

101. Eckford P, Sharom F: ABC efflux pump-based resistance to chemotherapy drugs. Chem Rev 2009, 109(7):2989-3011. 
102. Fletcher J, Haber $M$, Henderson $M$, et al: $A B C$ transporters in cancer: more than just drug efflux pumps. Nat Rev Cancer 2010, 10(2):147-56.

103. Ding $X$, Wu J, Jiang C: ABCG2: a potential marker of stem cells and novel target in stem cell and cancer therapy. Life Sci 2010, 86(17-18):631-7.

104. Shukla S, Wu C, Ambudkar S: Development of inhibitors of ATP-binding cassette drug transporters: present status and challenges. Expert Opin Drug Metab Toxicol 2008, 4(2):205-23.

105. Diehn M, Cho R, Lobo N, et al: Association of reactive oxygen species levels and radioresistance in cancer stem cells. Nature 2009, 458(7239):780-3.

106. Lomonaco S, Finniss $S$, Xiang $C$, et al: The induction of autophagy by gamma-radiation contributes to the radioresistance of glioma stem cells. Int J Cancer 2009, 125(3):717-22.

107. Phillips T, McBride W, Pajonk F: The response of CD24(-/low)/CD44+ breast cancer-initiating cells to radiation. J Natl Cancer Inst 2006, 98(24):1777-85

doi:10.1186/1479-5876-9-50

Cite this article as: Liu et al.: Cancer stem cell subsets and their relationships. Journal of Translational Medicine 2011 9:50.

\section{Submit your next manuscript to BioMed Central} and take full advantage of:

- Convenient online submission

- Thorough peer review

- No space constraints or color figure charges

- Immediate publication on acceptance

- Inclusion in PubMed, CAS, Scopus and Google Scholar

- Research which is freely available for redistribution

Submit your manuscript at www.biomedcentral.com/submit 